\title{
Religious Belongings in Multi-Cultural Schools: Freedom of Expression and Citizenship Values
}

\author{
Rosangela Lodigiani
}

\section{1 Introduction}

This chapter is aimed at presenting and discussing the main findings of the qualitative research illustrated in Chapter 21. Deepening the research findings by focusing on the basic concepts of religious freedom and citizenship rights, the chapter explores youth religious beliefs, spirituality and atheism in a context of "weak secularization" (Chapter 3 ) and illustrates how the school can be deemed as a public space to test religious pluralism. Religious diversity deeply and increasingly challenges the school intended as a secular and open place, by producing different, when not fully opposite, reactions: from neutralization of religion to the promotion of its cultural dimensions. However, the interreligious and intercultural dialogue developed within the school turns out to be a training ground for democratic citizenship, at least when aimed at fostering mutual knowledge, respect, acceptance of differences, and at sheltering from the temptation to reject different memberships because of a certain idea of secularism.

The chapter is organized as follows: $\$ 2$ briefly draws the theoretical framework and the research's aim and hypothesis. The subsequent paragraphs arrange the research findings around four main themes, by deepening:

a) the freedom of expression of religious belonging (that is, religious freedom and the worship of one God, of another God or of no God at all) in the school context -through the use of religious symbols too-, where there may be either ease, caution, indifference or lack of awareness $(\S 3)$;

b) the relation between religious plurality and the development of different "world visions", which calls into question the citizenship values and the differentiation of public and private spheres $(\$ 4)$;

c) educational students' and families' choices affected by religious beliefs, which show that issues that were thought to have been secularized finding a peaceful solution in the differentiation of private, civil and religious spheres-are coming back in the school debate (e.g. how to protect 
the right to freedom of expression, and what the boundaries of parental authority over children's education are) $(\$ 5)$;

d) the space for religious issues through and beyond the curriculum and in the daily school life: by enhancing different religious cultural heritage $(\S 6,7)$, the school becomes a "laboratory for dialogue", in which different voices co-operate for finding ways of living peacefully together (§8).

Scenario Outlines, Theoretical Framework, and Study's Aims

As described in the previous chapter, multi-ethnicity is becoming a structural and fundamental feature of Italian public schools. Actually, schools experience -and reflect-in a specific way what happens in society.

\subsection{A Brief Outlook on the Italian Context}

Since the beginning of the Seventies, Italy has started to record a positive net migration, reversing its traditional role and turning from an emigration to an immigration country. However, the increase of the foreign population, speeded up especially since the Nineties, began to be felt in the school system, due to the growing of migrants' offspring born in Italy to foreign parents or re-joined with members of their own family already settled in Italy. Some figures are useful for drawing the trend.

In the last two decades, the increase of students with an immigrant background has been exponential, and Italy reported immigration rates of foreign student, calculated on the total amount of students, close to the ones recorded in the European traditional immigration countries (Santagati et al., 2019): from $0.7 \%$ in the 1996/1997 school year, the rate has been rapidly increased to $7.9 \%$ in the $2010 / 2011$ school year and to $9.4 \%$ in the $2016 / 2017$ school year. Particularly in the last five years, there has been a surge of new migrant students, which can be partly explained by the significant rise in the arrival of unaccompanied minors, asylum seekers and refugees (Azzolini et al., 2019). Therefore, in the 2017/2018 school year, about 826,00o foreign students have been enrolled in the different educational levels of the Italian school system, which is characterized by an inclusive approach. The rate reaches $10.7 \%$ in pre-school, $10.8 \%$ in primary school, 9.7\% in lower secondary school, $7.1 \%$ in high school, respectively (MIUR, 2018). Moreover, alongside the second generations of foreign immigrants, a second generation of "Italians with migratory background" is growing, born to -or re-joined with-foreign parents who have completed the naturalization process, and who, together with the children of mixed couples, are legally indistinguishable from Italians students, except for some specific 
points of view -e.g. language, religious confession or other features- which make them fully belong to the second-generation "universe" (Molina, 2014). As the latter is a plural and diversified universe, we should speak about "second generations of immigration" instead of "second generations of immigrants"1 for a better understanding of the phenomenon.

The national outlook does not allow to appreciate the territorial differences that are relevant at the regional and, especially, at the local level: among cities of the same region or districts, or single schools of the same urban area. Foreign population is distributed unevenly along the peninsula and the highest number of students with non-Italian citizenship does not necessary result in the highest rates. Lombardy is the region with the highest number of foreign students $(207,979)$, equal to about a quarter of the total foreign students in Italy, while Emilia Romagna has the highest percentage of students' regional populations. Milan leads the cities ranking considering the absolute numbers, but it is not even among the top 10 in relative terms; however, in some districts and in some institutes, the percentage of students with non-Italian citizenship exceeds the majority, so as to have triggered -in some cases- the so-called "white flight" phenomenon (Pacchi, Ranci, 2017).

Beyond the statistics, Lombardy and the main urban centers of the region are interesting contexts to observe with regard to intercultural (and interreligious) dynamics in multi-cultural schools because of the long-lasting attention to this issue witnessed by the large number of studies carried out on education and on social inclusion of foreign students, ethnic inequalities in education etc. (Santagati, 2015). In line with this type of studies, as explained in Chapter 21, the research here presented focuses on 7 lower secondary schools (ISCED 2) in the Lombardy Region: 3 in Milan, 3 in Brescia and 1 Bergamo. ${ }^{2}$ These three cities gather about $37 \%, 17 \%$ and $12 \%$, respectively, that is almost two-thirds of the total amount of foreign student enrolled in the Lombardy schools; and Brescia is the fourth largest city in Italy as for the foreign students' rate.

1 As claimed by the youngsters with a migratory background. See, for example, "Rete G2" (G2 Network), a non-party national organization, founded -in connection with the International G2 Network- by children of immigrants and refugees born or arrived in Italy as children (http://www.secondegenerazioni.it/).

2 For more details about the schools and the persons included in the research, see Chapter 21 Focus groups' quotations reported throughout this chapter have been codified as follows: participants' gender, nationality, religious affiliation (if any), FG number, school province and typology of participants (students or adults, that is: teachers/school manager/school assistant or parents-mother/father). 
Due to the growth and expansion in the number of students with a foreign and migratory background, multiple cultural roots and religious belonging meet with each other in everyday school life, as in the whole society. The structural and stable changing in the ethnic composition of the classrooms underlines (in Lombardy as in Italy) the need to deal with the multi-cultural education issues and takes back to the very center of the educational debate the question of how to treat the students' different cultural and religious belongings in order to promote school integration (Colombo, Santagati, 2017).

\subsection{Beyond the School as a Secular Space}

As deeply discussed in Chapter 21, the revival of the role of religion inside and outside the school environment contrasts with the idea that religion belonging must be shut in the private sphere and should not interfere with the understanding of the public schooling as a secular, "neutral" space, with respect to different religions.

The core idea of a secular education in public schooling took shape in a scenario of increasing secularization, pluralization and "disenchantment" of the world (in Weberian words) of Western countries, Italy included. In this scenario, according to secularization theory, at the collective (political and institutional) level, the separation between State and Church authorities/religious communities became a central pillar of the "modern State", intended as "a nondenominational State", and of liberal democracies grounded on the fundamental rights of universal human dignity and equality and freedom of expression. That is, freedom of thought, conscience and religion, as affirmed by the European Convention on Human Rights (1950, art. 9), but firstly stated by the Universal Declaration of Human Rights of the Unite Nations (1948, art. 18). As for religion, this means: freedom to choose among different religions and between believing or not in any religion. It is worthy to add that, although the freedom of conscience, religion and worship is an inviolable right of the person, to be guaranteed to all citizens, the freedom to manifest and practice one's religion is not absolute whereas it is subject to the political legitimation within the framework of democratic laws and citizenship, as we can read -for examplein the above-mentioned European Convention (art. 9). All these statements, principles and liberties are clearly expressed and guaranteed by the Italian Constitution (particularly at art. 8 and 19) too, and are today acquired and recognized as fundamental part of the European legal and legislative culture (Chapter 4).

In this wake, in accordance with the process of functional "differentiation and specialization" of modern society -which represents the basic assumption of the secularization theory (Luhmann, 1982) -, Churches and religious 
communities increasingly confined their function to pastoral care by renouncing their competencies in other areas of society, schooling education included, while the State protects and promotes the rights and the general welfare of its citizens, without interfering in matters of faith. Simultaneously, at the individual level, religious believing and behaviors have undergone a process of privatization as there is a link between the functional differentiation of the religious system within the whole society and the individualization of religious practice (Habermas, 2014).

In other words, as argued by Ferrara (2009; 2014), secularism refers both to: (i) a political dimension, since the Churches and the State are clearly separated; all citizens can freely exercise their religious freedom and worship (or atheism), and the Church religious faiths are protected by the State, which maintains its "neutrality"; and (ii) a social dimension, since religious communities cease to influence law, politics, education and public life in general and become functionally specialized sub-groups, while religious rituals, symbols and boundaries of faith diminish their role in marking significant moments of people's lives, in shaping their thoughts, commitments, loyalties and their main concerns. As the author affirms, this distinction "allows us to pinpoint asymmetries and unbalances in complex processes of secularization. In some countries, at a certain time, political secularization may proceed at a faster pace than societal secularization" (Ferrara 2014: 68).

Within this framework, the implications of public schooling are supposed to be clear: the school has to focus mainly on its role of public and secular institution, by teaching civic and democratic citizenship values and competences, thus giving all students the same opportunity to access education regardless of their religious belief. Religion neutrality is assured through a curriculum that tends to expel "religion education" ( $\mathrm{RE}$ ) (whatever the solution adopted by the organization, in order to ensure religion literacy alongside the curriculum itself): religion should not interfere with people behavior outside their very private sphere, in school life as well in public. From this point of view, the French case represents a meaningful example, since it theorized and then applied the so-called "Republican model of integration", which turned into the "Republican model of indifference (to ethnic, but also cultural and religious) differences" (Ichou, van Zanten, 2019: 519-520; see also Chapter 24).

However, in the last few years, the scenario has dramatically changed, and the complexity and misalignment evoked by Ferrara has come to the fore.

As Habermas -among others-argued, not only "the loss of function and the trend towards individualization (did) not necessarily imply that religion (has lost) influence and relevance either in the political arena and in the culture of a society or in the personal conduct of life", and "quite apart from their numerical weight, religious communities can still claim a "seat" in the life of 
societies that are largely secularized", but even the awareness about the persistence of religion in the public arena is becoming "common sense" to the point that the awareness of living in a "post-secular society" is widely spreading ( $I b i$ dem: 63-64). In the author's thinking, three overlapping phenomena are moving in this direction: $(i)$ the rise of international and local conflicts connected to religious issues (terrorism and fundamentalism); (ii) the revival of the public role of religions in pluralist national contexts (as the Western ones), where a growing number of ethical dilemmas (i.e. abortion, voluntary euthanasia, bioethical new frontiers) needs a political regulation, which is hardly attained by ignoring Churches and religious organizations voices that push to enter and influence the public arena; (iii) the intensification of global migration flows that obliges to face the pluralism of religions, cultures and ways of life and the consequent challenges for social integration. As a result, not only people's awareness of the relevant role still played by religion in the public space rises but, more radically, the secularization theory itself ends up going under profound scrutiny (Rizzi, 2016; Chapter 3).

Public school -as the whole society-is put to the test of religious plurality, expected to be a secular and, at the same time multi-religious, context (Fabretti, 2013), and is called to reach two different aims: because of its status of public institution, being a secular place, not conditioned by norms and values of a specific religion; and because of its status of education institution, promoting religious education within a framework of mutual respect and tolerance about different religions. As highlighted in Chapter 21, due to the increasingly multi-cultural and multi-religious character of contemporary societies and schools, this twofold purpose becomes more challenging, turning into a "dilemma":

(i) being anchored to the "modern" idea of secularism (e.g. renouncing to delve into religious contents, ensuring that the school is recognized as a neutral space, a "free-zone" in which personal convictions and religious belongings are substantially ignored);

(ii) opening the door to the dialogue between different cultural roots and religious belongings, by teaching about different religions in a climate of mutual respect and reciprocal understanding.

\subsection{Study's Aims, Hypotheses and Questions}

Against this backdrop, this chapter seeks to explore how the Italian public school deals with these challenges; more in detail, the chapter aims at investigating what place is given to religion in school life and in the curricula, assuming that the capacity of enhancing (respecting, knowing) the (religious) differences as an essential part of personal identity can be a lever promoting school (and social) integration. In fact, through the research outcomes here 
discussed, we will shed a light on interethnic and interreligious dynamics in the school context, considering both vertical (between teachers/parents and students) and horizontal (among peers, and between teachers and parents) relationships, by scrutinizing if and how (in which forms and circumstances) religion affects them.

In our hypothesis, students' religious belongings (beliefs and values) -if dialogue is encouraged and adequately accompanied- promote social integration in the multi-cultural school context. Although it cannot be excluded that conflicts and xenophobic attitudes may arise inside and outside the classroom, we assume that when conflicts are properly managed, they may represent an opportunity to foster social cohesion and build bridges between cultures.

Following the whole project's theoretical framework, we can maintain that for both migrant and native students, personal belonging to a religion faces at least four cultural and social, individual and collective spheres of experience, here identified through the four keywords/lines of research outlined in Chapter 2: Identity, (Religious) Freedom, Citizenship, and Common good. These four spheres of experience are mirrored by the school context in a specific way.

The first term, identity, focuses the attention on the individual and collective processes of (re)shaping self-definition, based on religious beliefs and values, in the school environment. More precisely, it pushes for considering religion belonging as a fundamental "identity marker" (among others) in school relationships: among students, between students and teachers, between teachers and parents.

The second term, religious freedom, draws the attention to the legitimization of the pluralistic involvement of religious identities and affiliation in the school life, by guaranteeing the right to freedom of religious choice and expression. Many questions arise around the actual exposure of one's religion belonging through symbols and/or decisions and behavior, which clearly depend on it.

The third term, citizenship, concentrates not only on the normative (regulative and legislative) framework of religious freedom -in the Italian school protected by the Constitution and regulated through specific agreements between the State and different Churches, denominations and religious communities (Chapter 9)- but also on the contrasts that may arise among the multiple identities and loyalties deriving from the affiliation to a certain religion and connected to the specific place where one has grown up (in our case, Italy).

The fourth term, common good, directs the attention to the school (students, teachers, parents) strategies (if there are any) to enhance RE as a cultural heritage for the curriculum enrichment, to consider interreligious dialogue as a laboratory of "civicness" and participation. 
Within this framework, the field research aimed at:

(i) analyzing school life and school curriculum to see if, and to what extent, religion is "at stake", and which role it plays towards school integration;

(ii) describing the main patterns of religious-based behavior in multi-cultural schools (including symbols' usages);

(iii) gathering empirical evidences about the role of religion diversity in school integration;

(iv) deepening the issue of interreligiouss conflict in the classroom (see Chapter 23, specifically focused on interreligious conflicts and integration processes in multi-cultural schools).

The focus groups and the chances for a progressive deepening that this method entails allowed us to delve into three main themes: spontaneous outpouring of religious belonging; when and why (in which circumstance) the presence of different religious affiliations arises; how schools cope with religious plurality.

\section{Religious Identity and Freedom: Lights and Shadows from an "opaque prism"}

The issue of religious identity, explored through the spontaneous declarations of belonging at the very beginning of each focus group, shows, along with some elements of convergence, interesting differences between what students and adults think.

At first, consistently with other research carried out in the Italian multicultural school (Ottaviano, 2010), the presence of different religions in the classroom is perceived as something that tends to remain in the shadow and that is generally a-problematic, since it is considered neither a relevant matter of interpersonal relationships nor a lever for conflicts. By examining the issue more in depth, however, the picture becomes more complex.

Thanks to the preliminary content analysis carried out with Nvivo software, it is worth noting the sizable difference in the most frequently-mentioned words recoded during the students' and adults' focus groups. Selecting the only words with a minimum length of four letters and excluding religion(s)/ religious, school(s), student(s), teacher(s) - which, due to the guideline provided for discussion, are necessarily continuously utilized in every focus group- we find that students largely utilize the terms freedom and friend/ friendship, while the adults' narratives revolve around the concepts of differences/diversities, and especially gender and cultures differences (See Table 22.1). 
The uneven distribution of the most recurrent words reveals students' and adults' different concerns regarding the presence of religion plurality at school: as we will examine below, the former certainly have been influenced by the students' age (11-14 years) and the transition into adolescence that they are experiencing; the latter have been influenced, on the one hand, by their specific role -as teachers or parents-, and, on the other hand, by the composition of the adults' sample, in which female teachers and people belonging to the national and religious majority were over-represented. Beyond the frequency, however, it is more interesting to understand the semantic context in which the most recurrent words have been used and the meaning given to them. To understand these aspects, we need to go in-depth into the analysis.

\subsection{The Students' Point of View}

In the students' opinion, religious belonging remains in the backdrop of their identity until something happens and brings it back to the surface. They declare that religion is not influential neither in their interpersonal relationships nor, in more in general, in their daily life, both inside and outside the school. According to them, religion pertains to the individual, to the "private and emotional sphere", and certainly, it is not relevant in forging the bonds of friendship. It is therefore not important to talk about it, to address the issue openly.

On the one hand, there is a strong (idealistic) recall to the shared values of friendship and "common humanity": religion belonging is not important -they say- since friendship goes further, as all people are equal. "Friendship has no religion. Friendships are always friendships without religion. Friendship is not based on religion or nationality" are the most used phrases at the beginning of every focus group.

I don't care about religion or nationality because, actually, even if we belong to different religions, we are all brothers and sisters ... hence, we are all bonded together, nothing and nobody can divide us. (Female, Moldova, Orthodox Christian, F G 1 Bs, students)

On the other hand, the issue -as the students assert- simply does not concern them as young people, more precisely as adolescents with many interests but with no interest for religion.

Religion ... it's more for adults. Indeed, it's just for adults! As teenagers, we don't care so much about religion, because then it depends on what you like ... I like football and when we talk, we talk about hobbies and not 
TABLE 22.1 Most frequently mentioned words during the focus groups

\begin{tabular}{lllr}
\hline \multicolumn{2}{c}{ Students' F G } & & \multicolumn{2}{c}{ Adults' FG } \\
\hline Words & Frequency & Words & Frequency \\
\hline Friend/Friendship & 227 & Woman/girl & 350 \\
Person & 234 & Differences & 332 \\
Family/Parents & 225 & Family/Parents & 291 \\
Christians/Christianity & 180 & Culture/cultural & 165 \\
Differences & 158 & Conflict & 156 \\
Conflict & 149 & Italy/Italian & 143 \\
Muslim & 148 & Catholic & 143 \\
Freedom & 125 & Male & 136 \\
Nationality & 109 & Children & 132 \\
Italian & 93 & Muslim & 125 \\
& & & \\
\hline
\end{tabular}

SOURCE: AUTHOR'S PERSONAL ELABORATION

about religion, which is a bit more of an adult thing. (Female, Egyptian, Muslim, FG 7 MI, students)

It is not by chance that friendship is positioned at the top of students' concerns and thoughts. During the adolescence transitional phase, finding one's own place in the world and the process of identity formation require peer confrontation, from which depends one's own self-esteem (Jounisse, Hanye, 1992).

Beneath the surface, however, students' points of view differ. Once called to reflect on concrete experiences, on their actual relationships at school with peers of other religions, they reveal to be aware of their own (and other students') religious affiliation and the role that it actually plays in different situations. Religion may facilitate friendships among students affiliated to the same religion or hinder friendships with students that "are perceived" as belonging to a different religion. In other words, religion may connect students to each other or may bring differences to light.

In the first part of the discussion, however, religion is seen by students as any other personal feature that they may, or may not, have in common. As studies on adolescents have long been demonstrating, friendship is nourished by reciprocal and consensual validation: "reciprocity" lies at the root of friendship, thus giving to this bond a symmetric feature (in contrast with the asymmetry that characterizes parents-children relations). Moreover, adolescent friendship is based on a process of "co-construction of reality" that 
emerges through debates, discussions, compromises and negotiations, and that permits to participate in the "construction of each friend's life story" (Ibidem, 1992: 6o). In this perspective, religion may affect friendships firstly because "you do the same things, you go to the same places, you have the same school hours, you schedule the same activities...", and secondly because you share the same values and ideas, as many students concurred.

Going in-depth into the analysis, students admit that religion is a "sensitive" issue, which should be handled with care. It is something one can talk about freely, but with caution, as one can fear to be misunderstood or even teased about; something that makes you think of the other as an "unknown world", even when looking at the choices he/she makes at school, which are not always transparent.

Although students unanimously declare they feel free to show their religious beliefs, and part of them clearly recognize that religion freedom is one of their rights which are protected by the Italian law in public schools (see also Chapter 9), various participants show they worry about being teased and misunderstood because of religion and report that similar circumstances occurred to some of their classmates. This kind of worries could be an unavoidable implication of the typical adolescent's overriding concern -the inner personal need of being accepted/included as a boy/girl by the peer group- rather than an effective anxiety relating to religion diversity. However, many students' narratives converge on it within the majority (Catholic students) and the minority groups (with different religious belonging and/or ethnic origin): both recall circumstances in which they (or some friends of theirs) have endured sarcastic jokes or even religious bullying.

This should be a public school; hence we should take the fact of being free for granted! If one is a Muslim or a Buddhist, there is no problem! For example, I'm a Christian, thanks to my parents, even if I do not profess very much ... I do not really mind about it. It might be a problem for someone else, but that's the society's feature today, so ... (Female, Italian, Christian, FG 6 MI, students)

I feel free to express my religion, it's my right. That is all. The others could be against me, but I don't care. The only thing is that sometimes I have a problem in sharing my opinion with my classmates: they keep on bullying me most of the time. (Female, Egyptian, Coptic Christians, FG 6 MI, students)

I am Christian, I believe and I like religion. However, my classmates often say unpleasant things about my religion: I feel free to profess it, but sometimes they hurt me. (Female, Italian, Christian, FG 7 MI, students) 
Actually, freedom of expression seems to be an acknowledged and proclaimed right more than a fact experienced at first hand. However, the scarce ability to identify moments and contexts in which they benefited from religious freedom hides the fact that it is generally taken for granted. This is true especially for the Italian students who claim to be Catholics: there is little awareness that religious belonging may represent a means for their self-affirmation or selfdefinition, while the awareness arises among minority students and those who proclaim themselves to be atheists. Among the minority groups, however, there could be the habit to keep religion belonging to the foreground, as any other diversity markers, in order to reduce contrasts and possible stigmatizations. The fear of being excluded tends to prevail.

The classmates' religious affiliation is generally deduced from external behavior and personal choices: in this perspective, what they eat at the cafeteria, their behavior during gym time, their participation (or not) in educational trips, and -particularly- their use of some religious symbols (such as the Islamic veil and headscarf, the Sikh uncut-hair, or the Christian cross) are considered as relevant markers that bear witness more than any spoken word. Furthermore, consistently with some research carried out in other countries (Jackson, 2014), the students interviewed firmly support the right to wear religious symbols as an expression of their own faith. It is perceived as something compatible with the school (and society) multi-culturalism.

However, in mixed classrooms, religious symbols sometimes are misunderstood and thus inappropriately used to label classmates. They are even worn and utilized without being fully aware of their meaning, just as ethnic fashion accessories mirroring a style of clothing, hence it is not always possible to presume the religion belonging of a classmate by only observing the external symbols he/she wears. "There are girls with veils: thus, one understands that they are Muslim, but then there are also Muslims without a veil" is the laconic gloss of a Muslim male student from Pakistan (FG 1 BS). Another student echoes: “... it depends because ... maybe you can understand if a person is Indian from the traditional clothes he/she wears, but ... you don't recognize it ... that is, you cannot say yes, he/she belongs to that religion because ... one can be Moroccan or Indian ... and wear western clothes ... so it's difficult to understand" (Male, Indian, Sikh, FG 2 BS, students).

From the students' narratives, the idea that the veil (or other symbols) may be in profound relation with one's identity, as an external signal for self-affirmation and subjectivation - or even, as some research pointed out (Fassari, Pompili, 2017) for combating the stereotype that wearing the veil is an imposition suffered by girls and women, due to unavoidable family or community traditions - does not emerge. Few students try to understand whether the 
veil is a symbol of fundamentalism or just of cultural diversity: the curiosity to grasp their deepest meaning, or to wonder about it, remains latent.

Actually, students tend to simplify and stereotype classmates' affiliations, often confusing religious affiliation with physical appearance or ethnic origin with nationality. In their mind, Italian corresponds to Christian, or whiteskinned, by default, likewise dark-skinned corresponds to Muslim, to the point that discovering that there are Italian Muslims or white-skinned Muslims has been reported as something still astonishing.

The students' low familiarity with religion within the educational settings does not mean that the religious matter is expelled from school lessons, rather it is both a proper object of the RE lessons and an occasional object in other disciplines of study (we will further examine this issue below: §5). However, students complain that teachers rarely give room to a deeper reflection and that teachers' religious belonging (if there is any) remains generally hidden from their eyes.

As wondered by a Catholic, Italian male student (FG 1 BS): "We never speak about religion at school. Maybe this matter is something that teachers want keeping as private".

In a nutshell, religious identity and freedom of expression through symbols and daily actions emerge among students with different nuances: ease for someone; caution and distress for others; and indifference or lack of awareness for others. In any case, the sensitivity of teachers and school managers, together with a cooperative family-school relationship, can be decisive to let religious plurality enter the school as an issue to treat openly. To delve into the point, it is worth highlighting how adults deal with religious belonging at school.

\subsection{The Adults' Point of View}

In the same way as students/children, the largest part of teachers and parents involved in the focus groups (excluding the answers of the teachers of RE) initially declared that religion belonging should remain confined to the private sphere: teachers do not want to create barriers that hinder an open dialogue with students, and parents do not want to be misunderstood and prejudicially labelled.

According to some teachers, keeping religious identity into the private sphere is necessary to properly exercise their role in compliance with their own commitment to a secular education in the public school, for being super partes, tolerant and respectful towards the different beliefs of students (and their families), and avoiding to construct "walls" and barriers. Disclosing it -someone adds- could be counter-productive since exposing or talking about one's own religion and beliefs, or simply showing one's belonging through religious symbols, can produce frictions with students and their families. 
(Our own religion) is something personal ... so it isn't something to show off and it doesn't really concern school. It can, by the way, come out and you can talk about it and make the most of it in a specific context, in connection with a topic or something happening, otherwise it can't be useful. (Female, Italian, School assistant, Catholic, FG 2 BS, adults)

At school it is not relevant. Maybe because religion is something spiritual (...) something very personal, which we have inside. (Mother, Tunisian, FG 1 BS, adults)

Being Catholic, Muslim, Evangelical, it's a form of choice to be the unique human being one can be, who lives as a Catholic, as a Protestant and so on (...) people can't be categorized, because the truth, for me, has got lots of different sides, it can't be kept within bounds, only in one field. In this world, (...) we can't categorize, because if we do that, we withdraw; instead, opening to the others as individuals means to be universal, to be open towards anybody, towards differences, towards meeting and dealing with others. (Male, Italian, School manager, FG 5 MI, adults)

I'm an Evangelical, but I don' like labels, because behind a label there are a lot of prejudices and a lot of judgment, which prevents any dialogue. I don't do that, even if I'm deeply convinced, I'm observant and everything, but I prefer when people notice, thanks to my actions, my way of living and dealing with others and being an open-minded person. (Mother, Italian, FG 5 MI, adults)

Not surprisingly, unlike the students, teachers are more aware of the importance of religious belonging in the process of identity formation. According to some of them, religious beliefs and affiliations represent a habit that concerns a person's daily actions and relationships, and since they -the habit and the person-are one, the former does not need to be explained.

First of all, we all have something in common with the others, as human beings. (Father, Albanian, FG 3 Bs, adults)

Generosity, for instance, is an aspect of the religion I belong to and that I usually practice (...), generosity is something I have been taught for all my life, by the people who witness it, or anyway indirectly by the meeting I have had with God, so I bear it as my main characteristic ... In this way, I think I witness my religious belonging without saying it openly; even if I 
openly say I'm a Catholic to my students. (Female, Italian, Teacher, Catholic, FG 3 BS adults)

It is an identity element which is part of our way of being, if I am like that it is also thanks to my religious faith, my education and so on. (Mother, Italian, Catholic, F G 3 BG, adults)

Well, I'm a church-going Catholic (...) I don't see that as something I wear on the surface, but it must be your way of being; well, I'm a Catholic, but I don't play the Catholic, I believe, but I don't play that role. And my way of being a Christian Catholic has to be visible through my daily actions, through my way of acting and speaking, thanks to the choices I make. Besides, I'm convinced that every religion, the Catholic one, the Jewish one and the Muslim one must focus on the idea of meeting and on a constructive debate. (Male, Italian, School manager, Catholic, FG 5 MI, adults)

Called to reflect upon their actual freedom to express religious belonging, teachers and parents feel that they are completely free and are convinced that their students do feel the same.

I express my religious affiliation in an extremely free manner (...). For me, there is no such thing as not being able to freely express one's religious affiliation. (Mother, Italian, F G 4 Bs, adults)

When it happens during my lessons, I express my idea, my religious creed, without any problems. We often face the subject during our school activities, so, since I talk about it, even my students do the same (....) In practice, we often face subjects which lead to the religious aspect and to a constructive debate. (Male, Italian, Teacher, Catholic, FG 3 BS adults)

We don't have to put up barriers, I am (...) free, free, because I'm openminded, I'm Muslim, I pray, but I'm even open to talk about my religion ... (Mother, Macedonian-Albanian, Muslim, FG 3 Bs, adults)

However, two caveats are worth noting:

- On the one hand, adults, and particularly teachers, are fully aware that speaking about their own religion may create difficulties to students which are sometimes afraid of being teased or simply are less self-aware or their own convictions and beliefs, given their young age.

- On the other hand, teachers and parents agree that students have little knowledge about religion. In this regard, our research seems to confirm 
what mentioned above ( $\$ 2.2)$ : religion privatization and individualization tend to produce religious illiteracy and trigger religious indifference, especially among young people, among which those who declare themselves to be atheist and agnostic are growing in number. This phenomenon is increasingly visible in Italy too (Cadeddu, Melloni, 2018; Garelli, 2016; Melloni, 2014). Although the religious affiliation remains higher among the Italian population, compared with the average of the Western European countries, and Catholicism is still the first religion of the Country, a "flexible Catholicism" is emerging, making room for personal interpretations of religious precepts and for critical positions towards the Church (Garelli, 2012).

Maybe, there are more people who don't feel like sharing their religious experiences with Italian students, sometimes they feel ashamed or simply a bit afraid ... they are discrete ... sometimes it is hard to let their characteristics come out ... well, we need to follow some paths ... where they can feel welcomed and free to talk about it, to bring out their peculiarities. (Female, Italian, Teacher, FG 2 BS, adults)

The general trend is that students don't get to know other people's religion, because it is not an aspect that comes out at first. (....) I'm thinking about my classes, there are a lot of religions and students ... who find it difficult to get the right time to talk about their faith, their religion, and to express it through their way of being, so sometimes, they are, maybe, I beg your pardon for my words, "crashed by that aspect" (...). It is not something that comes out positively, it only ... comes out in a very superficial way ... I tease you because you wear a veil or because you don't eat this and that, so, well, I really don't think that what concerns the religious sphere is a bed of roses, I really don't think so; on the contrary, in my opinion, at school, they don't show their religious belief so much. (Female, Italian, Teacher, FG 3 BS, adults)

I feel that they don't give great importance to their religion (Catholic). What I notice, on the contrary, is that they have a great curiosity towards the Muslim religion. I notice that when we face the subject from a historical point of view, they keep asking questions to their schoolmates. Yes, they have a sort of curiosity but, in my opinion, it is not connected to the religious belief itself, but to their habits, which are so different from theirs, and they want to know why. (Female, Italian, Teacher FG 4 MI, adults)

We have freedom of worship, but it's superficial, young people don't think about religion; as I see it, teenagers and children, since we are talking 
about lower secondary school, don't talk about religion when they are together, even Catholic teenagers don't do that, common topics are: the way you dress, what music you listen to, what sort of mobile you have, so I underline it, well ... I don't even see it as a form of division. Just when they start to observe "the way they dress" then they wonder about it. (Mother, Italian, FG 3 BG, adults)

What is more, teachers are persuaded that parents generally acknowledge that the school can be a favorable place for their children to fully express themselves and their religious affiliation. At the same time, they seem deeply aware that a reciprocal trust can be reached only step by step. It's a long way to, a sort of learning path featured by open dialogue, commitment, willingness to listen to each other without prejudice.

I believe we have basic confidence in our school: families know their children are safe here at school and the message is, or at least I believe it is (a lot of mothers come to our school, well the general opinion is that, at school, children are at ease and teachers look after them). (Female, Italian, School manager, FG 2 BS, adults)

I sometimes have perceived that foreign parents -as long as you respect their children and they understand you are there to do the right thing for their children, and you devote to that- accept your decisions and are aware that all that you do is for their children's good education, they respect you. So, the basic choice is: I respect you and when I understand this, I accept any action or decision you make. (Mother, Italian, FG 2 BS, adults)

Besides a deep confidence in the school's ability to be a "common place for everyone", the awareness that conflicts and frictions may arise is widespread as well. When solicited to push forward their analysis, going beyond the abstract principles to describe what happens during and between the lessons in the school environment, the picture outlined by the adults becomes multi-faceted and some criticalities -concerning the school-family/teachers-parents' relationships, especially-are pinpointed. It is not by chance that, at this level, the parents' voice emerges more clearly. between the Public and the Private Spheres

Generally speaking, public school is perceived as an open and inclusive space, capable of assuring freedom of religious expression to all its members and 
stakeholders. However, even the huge complexity of the issue emerges, together with the need to be better scrutinized within the daily school life practice, where ideal precepts and concrete actions intertwine, and where the secular feature of the school demands to be preserved.

Religious belonging, in many ways, concerns citizenship rights and religious freedom, as defined above, that is: $(i)$ freedom to believe, as an inviolable right for the human person; and $(i)$ freedom to express one's faith within the given framework of rules and norms for a democratic coexistence (Bychawska-Siniarska, 2017). In other words, the full enjoyment of the right goes hand in hand with the fulfilment of the corresponding duties. Indeed, the multi-faceted feature of this relationship clearly emerges when we also consider the right to practice one's own faith.

The many dilemmas that may arise from the struggle due to the coexistence in the same public arena of different religious values and prescriptions, possibly contrasting some democratic values, have found a solution across the ages in the separation between the public and the private sphere. As mentioned above $(\$ 2.2)$, while it seems relatively easy to outline the relationship between the State and the Church (Churches) -which are two institutions- as the paradigm of secularization theorizes, it is much harder to trace the relationship between citizenship (human) rights and religious rights. The latter, in the name of a religious belonging, recall the need for religious practices to comply with the rules (and limits) of the democratic, liberal society.

According to Max Weber's lesson in The Protestant Ethic and the Spirit of Capitalism, for some aspects still unsurpassed (Rossi, 2002), any religion embeds ethical and moral principles as well as (what any religion considers) "civic virtues", values and norms, that is, an idea of what constitutes a good citizen, of how it should be the "right order" of society (together with the affirmation of the truth and of the universality of their assumptions). This occurs even if the relationship between the religious doctrine and a moral code does not follow a unique model, since it is defined in a specific (and differentiated) way for each religion. Therefore, religious affiliation affects individual and collective lifeconduct and coexistence. Consequently, human rights (and the relating universal and internationally protected legal code) and "God's rights" (specific religious law of the diverse religious communities and Churches) may collide with each other (Ferrari, 2017). Following the author, we may mention three main areas of possible ethical conflicts:

- The first area concerns religious practices expressing the right of parents to transmit their religious faith to their children, but potentially crashing with individual rights. A meaningful example is neonatal male circumcision, a fundamental practice both for Judaism and Islam. Practiced in the first few weeks after birth, therefore necessarily disregarding the individual consent, 
it leaves an indelible physical mark, which may be considered as a violation of the individual integrity of one's own body;

- A second area relates to the juridical status of women: human rights conventions prohibit any discrimination based on sex, whereas many religions prohibit ordaining women to the priesthood, prevent them from accessing other leadership positions in the religious community or gaining access to certain functions or jobs;

- A third area concerns the right to convert, that is to replace one's current religion or belief with another (on none), protected by the UN Declaration of Human Rights, but strictly banned (and even punished) from some religion systems (Ibidem).

Without further exploring these extremely controversial debates, these few hints offer a suitable framework to understand to what extent, in the contemporary plural society, it is difficult to establish, once and for all, the boundaries between different orders of law, and between beliefs and practices.

These arguments are breaching the wall among the scholars who reflect on the "post-secular turn", questioning the supposed religions irrelevance in politics and in public life. As argued by May et al., religion "is not simply concerned with supernatural entities and the nature and existence of a transcendental realm. It is also, crucially, a framework through which interpreting and responding to immanent contexts, events and experiences. Through symbolism, rhetoric, images, narratives, histories, myths, values and experiences, religious ideas and influences continue to intervene in, and unsettle, the supposedly ordered rational nature of secular politics" (2014: 339).

Clearly, the aforementioned controversies do not directly pertain to the school domain, but to the awareness that the relevance of these issues should be reminded in the school debate. As stated by Benadusi et al. (2017:478), the debates concerning the multi-ethnic and multi-cultural schools tend to switch "from the religions (viewed as spiritual and pragmatic systems for "ordering" the world) to religious beliefs (seen as systems of values and moral guidance for conforming to institutions and adhering to established religious practices)". The relationship between religious beliefs and power is particularly "circumvented or suppressed in the public discourse on religious teaching in schools and in educational curricula" (Ibidem), but its relevance deserves much attention. In fact, the school mirrors similar sets of problems and, in a way, allows us to focus on them better, as the separation between the public and the private spheres is daily challenged by the students', families' and teachers' behaviors and choices. The legal protections of religious freedom, while providing a crucial leverage for social integration, triggers claims for the recognition of the legitimacy of each religious belief and practice within the school life, by 
asking for a definition of borders between religious and civic loyalties - borders that no longer seem easy to identify.

As highlighted above, the different ethnic, cultural, and religion affiliations, burst into the school daily life mainly through external symbols and customs, like some peculiar eating habits observed in the school cafeteria (e.g. not eating pork meat, fasting, eating halal food) or some religious symbols worn by students (e.g. the Islamic veil). However, both students and adults agree that it is when these external symbols and customs start to influence people's behavior that they need to be handled in some way. The cases reported by focus groups' participants concern some "typical" circumstances, such as:

- The request -from some students (and their families)- not to be enrolled in the Catholic religion lessons or to be enrolled in them despite admittedly adhering to another religion or despite being atheist/agnostic;

- The request -from some female Muslim students (and their families)- not to attend two-days (or more) long school trips, and not to have male classmates seated next to them;

- The request -once again from some female Muslim students (and their families) - for a derogation to the dressing code, e.g. the request to wear only long pants during gym class or other special clothes for attending sports activities (e.g. swimming) or to skip swimming lessons.

Evidently, these are very different examples. However -although with different intensity - they all prove how much the distinction between the private and the public spheres at school is blurred. Furthermore, these examples prove the inner "power dimension" of school relationships and the religion's role in shaping people's (in this case, students') "world vision". Consequently, they reveal how thorny the recognition of religious rights at school is, not only from a cultural and religious point of view (pertaining values and beliefs) but also from a political one, lato sensu. Ethical and moral principles, as well as "civic virtues" (as intended above), are -more or less implicitly- fundamental matters of the religious socialization that students undergo within their families, and surface in some of the family's choices, preferences and prohibitions imposed to them in the school contexts, as well as in some students' behaviors, challenging the school's ability to properly answer as a public, secular, and plural space, and bringing the school-family relationship to the foreground.

\section{The School-Family Interface as a Keystone for Religious Socialization}

In a certain sense, the aforementioned requests brought to the fore what Charles Taylor theorized about the effects of secularism on religion, in his 
highly-influential book A Secular Age: "Believing in God is no longer axiomatic. There are alternatives. And this will also likely mean that at least in certain milieu, it may be hard to sustain one's faith. There will be people who feel bound to give it up, even though they mourn its loss" (Taylor, 2007:3). Religious belief has become a "social contingency". This assertion does not imply that believers experience their own faith with the sense of contingency or valuerelativity, but that our social world is now sufficiently pluralistic regarding faith-commitments, to the point that we no longer consider religion as what provides us with the default normative foundations for collective action (Gordon, 2008: 665).

Religion interpretation of the world cannot be longer taken for granted, since it is a possibility among others. The gradual loss of a fully shared common sense -that is, the "social imaginary" (...), the "common understanding, which makes common practices possible, and a widely shared sense of legitimacy" pushes forward for a "radical reflexivity" (Taylor, 2007: 171-2). In other words, in post secular society, religion turns into a system of beliefs that is both self-reflexive and aware of the pluralistic scenario in which it is definitively inserted. As underscored by Ferrara (2014: 70), Taylor's argumentation allows us to pinpoint a third dimension of secularism (together with the political and social ones, mentioned above), a phenomenological and "experience-near" dimension: "from the standpoint of this third variety of secularism, belief and non-belief, theism and atheism are not to be seen as rival theories, in cognitive terms, but rather as different ways of being in the world, of living one's life". As a consequence, the experience of believing has undergone a deep transformation: from being the unquestioned framework shared by everybody in a natural, unreflective way, to being one among other options available, and which can no longer be lived in an unreflective and naïve way.

Keeping this background, it is worth noticing that this self-awareness seems to be shared by all focus groups' participants. The major part of the narratives underlines the importance of reciprocal exchange of views on religious issues and related practices, even if this exchange may lead to some disagreement.

In this regard, two macro-issues deserve our attention: the process of religious socialization and school-family dialogue.

Not surprisingly, family is acknowledged as the main agent of students' religious socialization, even if the school and the peer group certainly contribute to it, considering that school is the place where the youngsters spend most of their time and build friendships. The opinions of students, teachers and parents converge in it: family plays a fundamental role in the transmission of values and religious heritage. Not by chance, family, mother, father, parents were among the most-frequency words counted by the Nvivo Word Frequency 
Query. The socialization role of the family is considered as pivotal, especially for families with a migratory background and their offspring. As some research has proved, it is an ambivalent role since it may favor or hinder the children's integration process inside and outside the school (Bichi et al., 2018; Ricucci, 2017).

Parents are seen as the legitimate custodians of the religious knowledge transmitted to children. Hence, they are also responsible for the quality of the religious education offered to them. The educational and socialization role of the family is considered to be so influential that, according to many narratives, students' behavior should be interpreted as a "direct consequence" of the teaching received at home, consistently with a "over-socialized" vision of the children that does not recognize neither the dynamic and relational nature of socialization process nor the active involvement of children themselves (Klingenberg, Sjö, 2019). What is more, this vision does not take into account that religious socialization is a process occurring in several different settings simultaneously, since there are many different ways in which young people encounter religion (Ibidem).

By the way, recognizing the family as a fundamental agent of religion socialization leads to highlight the responsibility that falls on parents' shoulders, and the controversial aspects that may arise from the clash between, on the one hand, their influential role in children's identity formation and, on the other hand, the peers' and school's (and media's) influence that increases during the adolescence, thus eroding parents' authority.

Approaching the issue, both youngsters and adults participating in the focus groups somehow "theorize" that all the families shape children choices, behavior, and beliefs regarding, for instance:

- Which religion to follow (and whether or not to follow one);

- Which choices and behavior to adopt at school: attending religion lessons or opting for alternative activities;

- Asking to skip some school activities (gym, journey, etc.) or to receive a "different treatments" (e.g. to dress differently, to choose who can be sitting by one's side),

- How to judge other religions and cultures, (power) relationships between people, teachers' and families' respective roles and boundaries of authority, currents events, etc.

However, moving on from this common "theoretical" vision, when narratives refer to personal experiences, both students' and adults' attention focus on two main issues:

- Freedom of religious choice;

- Role of women according to religion beliefs. 
Notwithstanding these similarities, their opinions diverge for some aspects that we need to mention, considering: $a$ ) students' and $b$ ) adults' voice separately.

\subsection{The Students' Point of View}

On the students' part, attention is paid to the freedom of religious choice, that is as a matter of possible controversy within the family relationships.

Students belonging to the majority (Italians and Catholics) generally consider their experience of freedom of religious choice as something just acquired and a-problematic. Being aware that religion affiliation is a relevant family's heritage, they feel free to change religion if they want to. They generally express gratitude for family education, for the values passed on to them and for their religion's legacy, as well as for the freedom of choice, thought and act that they admit to benefit from. At the same time, they firmly criticize what happens to some of their classmates belonging to other religions, who -in their eyes- are conditioned and limited by family impositions that they cannot bypass and that can hinder their personal freedom and their transition to adulthood. Indeed, some students with a migratory background -mainly girls professing Islam, but also a couple of Catholic non-Italian native students-reported to having to endure family impositions. However, this is a controversial issue and no generalization can be applied to the relating narratives, as the following few ones show.

I would like to live on my own ... I want to have two dogs, not just one. I don't know ... I feel under the control of my parents. (Female, Italian, Catholic, FG 1 BS, students)

I'm Muslim too, but I'm not like her, they don't oblige me to stay at home, I go wherever, whenever I want! (Male, Senegalese, Muslim, FG 1 BS, students)

We are free, but we are on probation, because our freedom is also limited by some factors. For instance, I would like to be Buddhist, but I'm influenced by the others, what my friends and relatives think about me. (Female, Italian, Coptic Christian, F G 6 MI, students)

We are oriented since our birth: our parents influence us a lot. When you have Christian relatives, it is difficult (to change), because you are used to specific habits. (Male, Italian, Atheist, FG 6 MI, students) 
I agree, there are religions and religions ... Maybe there are stricter parents who, according to their beliefs, tell their children they must do what their religion says, that's it; on the other hand, other parents may say that ... their children can dress as they like and believe in what they want ... they are free. (Male, Moldavian, Coptic Christian, FG 3 BS, students)

In religion they cannot oblige you, because if you don't wear a veil you are not doing anything wrong. (Female, Kosovara, Muslim, FG 3 BS, students)

In her religion there is no law which states: you must wear a veil, it's a tradition which has been passed down. She says: "I wish I could take it off, but ... my dad actually obliges me to keep it on". According to her, that's wrong, because nowhere it is mentioned that we must wear a veil and she told me that, actually, it just happens because men oblige women to do that. (Male, Italian, Catholic, FG 5 MI, students)

What is more, students debate on the role of women in the family, at school and in society, as an issue considered to be strictly connected to some religion beliefs and visions of the world. Here, the narratives become even more controversial, enriched by both personal experiences and (above all) stereotypes, prejudgments and hearsay, particularly dealing with:

- Restrictions that (in the Catholics' opinion) some female classmates suffer because of their family's religious beliefs concerning especially the duty to wear the Islamic veil, the prohibition to participate in school journeys or to attend some sports lessons, etc.

- The idea that girls/women have to play a subordinate role in some "traditional" families and are subjected to specific restrictions at school due to religion prescriptions.

The example provided by the above-reported students mainly revolve around Islamic religion, but narratives often overlap and confuse religion affiliation and nationality, without being capable of distinguishing between migrant, cultural and national backgrounds. A meaningful example is represented by the narratives focused on some Pakistani or Egyptian girls and families, whose religious belonging to the Islamic religion is presumed, but not really known by participants. Although the students consider this issue as a potential source of conflict, their discussions tend to remain on the surface, simplified and polarized upon few circumstances in which they assume the passive role of the girls as an unavoidable outcome of parents' impositions on daughters. The "asymmetric vision" in the participants' narratives (between what, generally 
positively, happens to oneself and what, negatively, may happen to the others) can be due to the composition of the focus groups (too many majority students). However, it can also reflect the students' difficulty in revealing situations personally experienced as problematic: it is easier to talk about yourself in the third person than being exposed to collective judgment. To "break the circle", there is the testimony of a young Pakistani and Islamic girl, who tells her experience in first person.

For instance, Muslim people treat women in a peculiar way, while the Christians or people from other religions treat them in a different way. In my family, we only have one woman: my mother; we are all males because I have two brothers and a father and, obviously, we treat her well, but our Muslim neighbors, I don't want to say, they treat women badly, but they don't have the same rights as men ... I hear them (...) Well, it happened once that the Muslim family had to go somewhere, but the woman couldn't do that ... so she had to stay at home for two days, because, as I figured out, the family was on a 2-day trip; on the contrary, we always take my mother with us ... I mean, there are some differences. To tell the truth, there are some Muslim families that are more open-minded and others that are stricter, my neighbors are open in comparison with others I know, some other friends of mine ... (Male, Romanian, Orthodox Christian, FG 4 MI, students)

When we go to school we don't care about our different religions, we are all together and we are used to living together, even if we have different religions ... we know everything about each other. However, when we are with our parents, Muslim people have more problems -at least this is what I have noticed- while Christian students don't have this many problems, if they want to talk with their parents about what they want to do. It's harder for Muslim students because we live in a prison ... believe me, my house is a prison! Up to a few months ago, I could not even get out of my house, except for going to school or to the mosque, nowhere else (....). Over the last few months, I only have been to the library twice, nowhere else. They don't let me go out so much. On Saturday they take me to the supermarket, otherwise they leave me at home ... I feel like living in a prison and I want to go out more often, I want to run away from home because I don't like it, I don't like to live there ... I want to live like the other students, but if I say so, they get angry, the only thing they can do is to force me ... (Female, Pakistani, Muslim, F 1 BS, students) 


\subsection{The Adults' Point of View}

On the adults' part, the role of family in children's religious socialization is acknowledged as particularly influential as it is the first agent that instils customs, values, social norms, social roles, etc. For better or for worse, hence, family is considered to be responsible for students' behavior at school, behavior that "certainly reflects" -as it is said- "what they 'breath' at home".

I think that teenagers and pre-teens, in general, at a religious level have more freedom of expression. I think that one of the limits is given both by their parents' culture and by the culture in the school educational orientation, which may have been more or less evident according to their different religions. (Father, Italian, F G 4 BS, adults)

The question is that in dogmatic families (not necessarily Arabian families, there may even be some very integralist Catholics, who despite the very inclusive message of the Gospel, show suspicion) there may be an impact on teenagers, thus, their behavior reflects what they hear at home (...). In my opinion, students are inclusive with other young people, but the influence from their families may cause a sort of cultural resistance, which leads them to be more suspicious. (Female, Italian, School manager, FG 4 BS, adults)

I sometimes see mothers wearing a veil and daughters without it and the other way around. I even met two sisters, one was wearing a veil the other one was not; their mother wasn't wearing it either ... I see, you understand, they perceive in their families a sort of approach that, according to their personality and growing-up process, leads them to choose to wear it or not, despite their mothers. Well, you can really feel the difference ... I've noticed that change over the past few years. (Female, Italian, Teacher, FG 1 BS, adults)

For the two Muslim girls who wear the veil, who are attending their last year here and are about to move on to the secondary school, the choice has been conditioned (...). (It would be necessary) to free them from a situation of "closure", in that case, really, because of the father ... They do the school that the father decided for them. (Female, Italian, School manager, FG $4 \mathrm{MI}$, adults)

Teachers and parents agree that the issue of freedom of religious choice is generally easy to be addressed at school. Besides being quite sure that their children 
can freely express their religious belonging at school, parents declare that they can make their choices about their children's participation in religion lessons, or in other activities, peacefully and, even if not Catholic, they are often open to a better understanding of the Catholic religion teaching, which is provided by every Italian public school within the curriculum (see Chapter 21 and $\$ 7$ ). In some cases, IRC teachers reported to have had (and still have) Muslim (or belonging to other religions) students attending their lessons with the consent of their parents, or to argue with parents about the desire of their children to attend IRC against their opinion. All the reported controversies, however, came to a positive solution. Similarly, some parents say they have had to discuss with their children the choice of attending IRC because their children wanted to attend it against their will; even in this case, their experiences have been generally positive. On the other hand, it is interesting to notice that teachers stress its importance to let students and families know more about the "non confessional" aim of IRC, so that these classes can be shared by students from different religions and different cultures in a better way.

Compared with the students' focus groups, the adults' ones revolve more on the gender relations, differences, inequalities and even conflicts. To the adults' eyes, these are very critical issues to address. Teachers' comments are largely negative on this, by reporting examples of parents (especially the fathers) impeding daughters from participating in some school activities, obliging them to wear the veil, and prevent mothers to talk with teachers. In this regard, however, we must remember that the adults' focus groups are mainly composed by women, Italian teachers who turned out to be particularly sensitive to these issues.

Although adults are generally more able to think critically than youngsters, their narratives are sometimes affected by stereotypes and simplifications (e.g. by considering people/students with the same ethnic/religion/cultural background as a homogeneous group) as well. Unlike the students, the adults consciously try (and hardly succeed in) distinguishing the reasons of gender disputes. For someone, these are rooted in a specific religion background and for someone else they are connected to the personal mentality or to a system of cultural beliefs rather than to a religion. Indeed, they think that prohibitions to girls and women are a "radical" and "betraying" way of interpreting religious precepts or a heritage of a patriarchal mindset and household.

It is a cultural problem and it relates to a religious vision ... it is useless to bury our heads in the sand, well ... beyond some sorts of integralism relating to religion, there is also a vision connected with (women's role). May be inside the family the woman has some freedom, but outside she is not allowed to do much ... It is especially true with Pakistani people: they have a more restricted vision of religion. I'm talking about the Muslim 
one, which creates troubles for us, even as teachers, because starting from the swimming pool for girls and other stuff there is a prohibition and that's it (...). We can even talk about Jehovah's Witnesses and other situations ... I mean, when the cultural and religious vision is very restricted, or anyway when religion becomes an alibi even for some cultural choices, it is clear that it is hard for us with our students, but also for students too ... (Mother \& teacher, Italian, FG BS 1, adults)

I would like to focus on the gender difference, because, according to my own experience, not only as a school manager in a school for one year and a half, but also as a teacher, I have faced some episodes which made me wonder about it. Once, it happened with a Senegalese student ... let's say a very "lively" student ... I told him "Well, I want to talk to your father» and he answered "My father is not interested at all in what you say because you are a woman". As a matter of fact, his father was only in contact with the School manager who was a man, at that time, and the ICT teacher who was a man as well. Anyway, I think this relates to some people, rather than to their religion (...). I think it's a cultural question, rather than a religious one. (Female, Italian, School manager, FG 7 MI, adults)

They say they are subjugated, but ... religion has nothing to do with it. I'm a Muslim, I know the Quran and I know what I'm saying ... really, it has nothing to do with it, it is not mentioned anywhere that you have to be subjugated to men and that they are supposed to decide for you ... (Mother, Tunisian, Muslim, F G 1 Bs, adults)

\section{School-Family Dialogue: Boundaries of Responsibilities and Religious Reflexivity}

On the whole, the teachers' efforts are aimed at addressing the demand for recognition of different cultural and religious backgrounds through a "familyfriendly approach" that needs to be "child-centered", geared towards the full respect of each child's identity. By asking for the recognition of religious identity at school -and, hence, asking for different ways to handle some aspects of school life in order to meet the values, the customs, and the practices relating to religion affiliation-families request that teachers (and school managers) opt for an intense dialogue, negotiations, argumentations.

Apart from an overall positive appraisal of school-family relations, teachers neither diminish the difficulties met to carry on a constructive debate nor hide the failures suffered. At the same time, they also point out the crucial relevance 
of such an effort, since it proved to be a profitable way to overcome barriers and to build reciprocal trust in the long run, even creating new chances for emancipation for some foreign mothers, once asked to be involved in their children's school life.

(it is difficult) especially with young girls, for instance when we have to go away for a couple of days ... Two years ago, for the first time, a girl was allowed to come with us (on a school trip). Her family had accepted, because they trusted us, it's just a question of trust, we had built that trust, otherwise they would have said "no" for sure ... (Mother \& Teacher, Italian, FG 1 BS, adults)

(...) On another occasion, a young girl wished her mother could come to talk to her teachers at the general school meetings, she really wished she could, so this lady in a burka came and told the teacher: "If my husband finds out I'm here I may have consequences". So, we got worried and said: "Madam, go home right now to avoid any kind of consequences". That lady was a newcomer, she had just arrived. Now, let's say, we still have contacts with this family and things have changed a lot, as they have been living here for a while ... (Female, Italian, School manager, FG 3 BG, adults)

The Pakistani experience is very strong here, in my opinion ... It is the result of the typical narrow-mindedness of this nation, with its habits and customs, which are strictly controlled and tied to religion. We have had boys in our school institute who went home and "tipped off", if I may say so, that the girls in their neighborhood or the daughters of some friends were not wearing a veil or just wore it on their shoulders rather than on their heads ... A young girl had been badly told off by her family because of that ... but some other things have improved a lot. I have seen Pakistani women who were very proud because they had come to school meetings and could sign documents: then, sometimes, they asked "Could you write down the things you are telling me? So, my son will not tell my husband that what I'm saying is not true..." Can you understand that? (Female, Italian, Teacher, FG 1 Bs, adults)

Together with the local intercultural contact, we have been organizing meetings with parents, actually Indian mothers ... We had a meeting last year and one at the beginning of this year and we noticed some confidence in our school. A lot of mothers come to our school, and the message 
we get is (or at least I believe so) that at school (their children) are at ease and their teachers look after them. (Female, Teacher, Italian, FG 2 вs, adults)

Foreign mothers come to the general school meetings and apparently this is, let's say, a way to get their revenge ... my impression is that some foreign mothers take a sort of revenge because they come to school as if they were "fathers" who want to know about their children's school life, and this is something typical here ... Well, it is not that widespread because it is usually the fathers' task to come to the school meetings, isn't it? But actually, a lot of mothers have come to our school meetings (Female, Teacher, Italian, FG 2 BS, adults)

What is more, the teachers recognize the need to consider carefully the ethical dilemma concerning the "boundaries of responsibilities" between school and family: to what extent can teachers discuss families' decisions? Which are the limits of parental authority over children's education? How to protect the freedom of expression with regards to religious plurality, in compliance with the school's "laïcité"? As a matter of fact, issues that were thought to have been overtaken by the secularization process -finding a peaceful solution in the separation of private, civil and religious spheres- can be found again in the school debate.

In addition, teachers underline that generalizing may lead to wrong conclusions. Circumstances are complex and implications relate to the personal attitude of people who experience them: the religious belonging is not at all "predictive" of a specific kind of behavior.

On the one hand, there are minorities, with a culture different from the Italian one and a religion different from the Catholic one, in which there may be frictions and reasons for disagreements - never easy to handle effectively. As this story emblematically witnesses:

We had the case of a Muslim student, a girl who lived her religion as an imposition, she wanted to integrate, but could not because of his extremist father. She was always accompanied to school, walking a step behind, she could not walk side by side, she could not attend the gym, she could not remove her veil in the classroom, she could not play music, watch movies ... The nice thing was that she had found solidarity among the classmates. Whenever she entered the school, she took of her veil asking them not to tell outside ... At a certain point, we fought because her father no longer sent her to school ... and had arranged a marriage: she had 
to go to her country of origin to get married. She used to say “I don't want to get married and with a man older than me". We managed in some way, involving the Social Services, to let her conclude lower secondary school with the final exam. But, unfortunately, after that she disappeared. (Male, Teacher, FG 5 MI, adults)

On the other hand, some minority families are actually eager to encourage their children to deepen their cultural and religious roots, and to open up to a constructive debate with others. This behavior, which is characterized by "willingness to know", appears even at school: the students with a migration background, from another culture and religion, are often more "experienced" when it comes to religion and more curious about other people's religions.

The foreign student is always called to reflect on ..., so he/she has a greater awareness. (Male, Teacher, FG 5 MI, adults)

We sometimes feel embarrassed, it has happened several times, even with a colleague of mine and her pupil, when the teacher of the alternative subject to the study of Catholic Religion was absent, the pupil had stayed in class and before the following lesson he said: "I want to stay because I'm interested in what the teacher says ... and I want to attend this class as well". (Female, Teacher, FG 1 Bs, adults)

The parents participating in focus groups do not reveal much about the matters of these subjects, but some of them say that their children's school experience, their willingness to follow (or not) religion classes and other school activities, encourage them to get utterly informed, to explain the deep-rooted reasons behind their choices to their children.

In any case, the coexistence of different religious belongings (including the non-believers) both at school and in society, may lead adults and young people to develop reflection, self-awareness and reciprocal dialogue. Indeed, these forms of understanding can favor integration, due to the capability of transforming such attitudes into an effective, constructive debate.

\section{$7 \quad$ Religion as a Transversal Content of the School's Curriculum and Cultural Heritage}

Within the given theoretical framework, the last issue that is worth being considered concerns the strategies enacted by schools to cope with students' 
religious diversities through and beyond the curriculum and the corresponding consequences. Besides RE (whose teaching is guaranteed in Italian public schools for those who select that option; see Chapter 21), the different subjects offer several opportunities to speak about the religious diversity.

Students and adults agree with the idea that the school -as far as it is described as an inclusive space, where everyone feels free to express his/her religious belonging-is not always capable of meeting students' need to delve into the religion knowledge and to discuss it. A number of narratives underline that there are many chances to speak about religion offered within the several disciplines -e.g. literature, history, art and music- but few are the circumstances that allow teachers to develop an in-depth debate. Despite this, teachers try to take advantage of the school curriculum, of the religious festivities and of the daily news that in some way regard religion, to solicit the attention of students for religion issues.

I don't talk about my religious beliefs at school, but as a Geography, History and Italian teacher, I really like to explore the historical root of someone who practices one religion or another. And I should say I have always had positive experiences, even with religion teachers who aimed to avoid catechesis at school, and rather focused on the history and culture of the country we live in. For instance, we can reinforce that with the "Divina Commedia" or with art history ... (Male, Teacher, FG 3 BG, adults)

Consequently, by grasping only the anthropological and cultural dimension of religion, the subject focuses more on habits, customs, folkways, and religious traditions rather than, strictly speaking, on religious faith. It does not tackle the main issues that each religion deals with, such as the "ultimate questions" and the corresponding answers, nor does it explore the transcendent dimension and the claims to truth, which are at the basis of every religion. The connection between faith and culture is dialectic and unavoidable, and even mutually beneficial (we may say that religion is a "cultural fact"). However, the distinction between the two fades out in the perception of the interviewed people. Furthermore, some of them see the risk of reducing religion to a mere type of culture, losing the connection with the transcendent dimension, which instead represents the distinctive contribution that religions may give in the contemporary society (Magatti, 2018).

Culture and religion are not separated, because culture develops together with religion and religion turns into culture, they are strictly connected. (Male, Religion Teacher, FG 3 в , adults) 
This is, maybe, something inevitably related to the above-mentioned third dimension of secularization (phenomenological and "experience-near" dimension), which reduces the experience of faith to one of the possible points of view coexisting in the common life.

Actually, thanks to the teachers' narratives, we can grasp that $\mathrm{RE}$ is not fully exploited for adequate insight because of the lack of suitable didactic means. Moreover, even though RE does not follow a dogmatic approach and cannot be identified with a confessional teaching (catechism), students, who do not attend it, have a limited knowledge of the contents they deal with.

Religion teachers especially want to emphasize that in their lessons they focus on the dialogue, by carefully taking into consideration different religions; moreover, they concentrate on developing ethical and universal issues.

Actually, they say it is a Catholic religion class, but we teach the history of religions, it depends on the (school) program we have. During the third year, we teach all the values ... Life as a gift, from the beginning to the end, so we consider all the issues regarding procreation, abortion, euthanasia, all those things, which do not concern Catholic religion only. (Female, Religion Teacher, FG 3 BG, adults)

For years, I have been encouraging foreign parents to be curious and to come and talk to a Religion teacher because we don't teach catechism, we don't teach any doctrine. (Female, Teacher, F G 1 Bs, adults)

At school, we experience humanity. (Male, Teacher, FG 3 BG, adults)

There is a Muslim boy who always wants to stay in the classroom and have religion lessons with me, I sometimes let him stay with me and he doesn't leave for the alterative activity ... but his parents told me not to do so, at present ... but he told me that next year he will come. (...) In my opinion, it is also a question of information, maybe they don't know what we do during Religion classes ... teaching Catholic religion is not teaching catechism, catechism teaches you to believe in one God, but the IRC is not only that ... I teach you some values and it's up to you to stick to them or not. (Female, Religion Teacher, FG 3 BG, adults)

Although some scholars critically assert that the Italian public school still remains Catholic-centric ${ }^{3}$ (e.g. it affects the annual school calendar), over time,

3 So that, Pace (2005) spoke about a "Catholic model of secularism" to underline the persistence of Catholic Church's influence in the public school and, more widely, in the public sphere. 
the changes introduced have been huge, due both to the acknowledging of public schools as secular and plural spaces, and to the growing number of students with different cultural and religious background. As a matter of fact, within the secular setting of the Italian State, the acknowledgement that the Catholic religion is no longer the only religion of the country, and that the latter is increasingly becoming a pluralistic (multi-cultural, multi-religious and multi-ethnic) society, have pushed to renew both the historically privileged and exclusive relationship set between the Italian State and the Catholic Church and the regulation and content of RE (Giorda, 2015; see Chapter 21). Regarding to the IRC, these changes -reinforced by the increasing numbers of foreign students (Catholic or not) attending the lessons- have pushed to rethink its content, opening it to the religious pluralism and adopting a "cultural perspective" (Frisina, 2011).

Despite this, the research shows that some contrast may persist between two opposite ways of understanding IRC: one more pluralistic, the other more conservative and confessional. Indeed, the translation in practice of this "new deal" appears to be uneven across the education system, "depending partly on the training and sensitivity of the RE teachers and partly on the local (social, scholastic, ecclesiastic) context", also resulting from the school autonomy ( $\mathrm{Ibi-}$ dem: 267). Likewise, the right to freedom of choice -formally proclaimed-is hardly guaranteed as equally on the substantive level, since it may happen that no alternative activities (or only low-quality ones) are arranged for students who would attend them (Giorda, 2015). However, these criticalities remain in the background of the narratives collected though the focus groups.

Students seem to appreciate the "new deal" of IRC, underlining that it is an opportunity to understand the differences (not only the religious ones) they find at school. Simply considering the fact that there are students who do not attend IRC, in fact, encourages reflection. Those who attend Religion classes assess them positively and more than once suggest that everybody should attend them (whatever religion they belong to, including non-believers), since it is a precious opportunity for debate. Because of this, students agree that a Religion class should be called, in a more explicit way, "the class for religions".

Something that disturbs me relates to the students who abandon the Religion classes because they belong to another religion ... In our school program, next year we will deal with Buddhism and all the other religions, so, as we learn about other religions, the other students from different religions can attend our Religion classes; because, by the way, it's an opportunity for discussions. (Male, Italian, Catholic, FG 4 MI, students) 
Religion classes are not only important for one religion, but for all of them because students can learn a lot in any case. (Male, Romanian, Orthodox Christian, FG 4 MI, students)

Indeed, religious pluralism at school may be restrained by two facts: firstly, there are almost only Catholic students attend IRC, and secondly there are only Catholic teachers who have the task to speak about other religions - hence, from a point of view which is (more or less implicitly) mono-confessional.

We lack places and time for discussion, because even when I teach my subject, that is to say the IRC, well, very often the group is only made up of few Christian Catholics. So, starting a dialogue with different religions is really complicated. Even if we should deepen the study of other religions, we would do it exactly as we do with all the other school subjects ... There is no close relationship with the students who live and belong to a different religion ... So, well, according to me, that class, that is to say the Religion one, would be a "good" one, in order to talk and go deeper and deeper into details about different festivals, ways of dressing, eating habits and so on, but in my opinion we hardly ever use Religion classes for that purpose. (Male, Religion Teacher, FG 3 BG, adults)

In the first year, according to the school program, I always deal with the Jewish roots, so we study the Torah, the Jewish Bible and then Islam, the structure of the Quran, we read something ... Then in the third year, we go on with Buddhism, Confucianism ... to show that ... the man who is behind that can express himself in different contexts ... As a Catholic religion teacher, I am not worried about talking about my religion, so ... When you teach a subject, you cannot separate it from its essence. (Male, Religion Teacher, FG 5 MI, adults)

Maybe, in order to open up to a more constructive debate, we might decide to make Religion classes compulsory, on a State level, not as Catholic Religion classes but as the classes about the history of religions based on constructive debate. That might be interesting. (Male, School manager, FG 4 MI, adults)

Recalling the seminal Eisner's work (1985) on the different levels and types of school curriculum, which weave together in the school ${ }^{4}$ - we may conclude

4 The explicit curriculum is the formal one, intentionally communicated; it refers to what is designed to teach, to the contents, goals, resources, documents etc. that are included in a 
that no teaching and no curriculum can be considered as "neutral" choices. Teachers' narratives confirm that teaching is intertwined with socialization processes and that, especially through the hidden and implicit curriculum, socialization's formal and informal dimensions penetrate each other (Besozzi, 2017). As a consequence -with reference to the Religion teaching -as to any other subject- teachers implicitly convey their expectations and preferences to students. Moreover, when you teach something, you deliberately choose not to teach something else (actually, by giving shape to a null curriculum): you cannot teach everything, obviously, but what you choose to teach does not reflect only a specific vision of the discipline and of the "state of the art", but also what the school (on the teacher) believes should be taught/neglected in light of its own vision of the world.

\section{Giving Citizenship to Religions at School: a Training Ground for Democracy}

Although public education has totally taken over its role as a secular and free context, we still have to consider the issue about religious differences. How does the "laïcité" of its mandate can be observed, together with a correct consideration of pupils' religious identity? The adults involved in the focus groups complain that this mandate might be misinterpreted, often resulting in a total denial of the different religious belongings and, thus, limiting opportunities for dialogue and critical thinking.

For instance, I'm against professing a sort of laicism as anti-religion, that is to say "State school: let's stay without symbols and crosses". On the contrary, I believe in people's spontaneity, which can be expressed without showing it off, anyway having something that refers to our religious belonging cannot be considered as bad if this is used to launch a sort of crusade. I find the attempt to cut off differences to be negative, because it

(written, official and public) lesson plan and teaching programme. The implicit or hidden curriculum consists of all the messages that are conveyed indirectly, without being stated explicitly, which regards teachers' attitudes, preferences, values, and expectations not included in the formal curriculum (e.g. meta-messages and "implicit theories" embedded in every teaching style), as well as the school setting (organization structure, physical characteristic etc.). The null curriculum is what schools do not teach, which may be as important as what they teach, since schools teach much more -and much less- than they intend to teach; it regards "the options students are not offered, the perspectives they may never know about -much less be able to use-, the concepts and skills that are not part of their intellectual repertoire" (Ibidem: 107). 
forces human beings to suppress one of their inmost parts, which because of culture or nature- may on the contrary be important. (Male, School manager, FG 4 MI, adults)

There is a misleading idea that laicism does not favor a constructive debate or the presence of the Catholic religion at school. We should remind everybody that the 1984 Concordat recognizes the presence of the Catholic religion because it is part of the Italian cultural heritage. By the way, at present, the discussion (even online and on social media) aims to limit this aspect as if it was a threat to people's freedom. On the contrary, I would say that, from this point of view, we need to protect the sense of belonging, because if people cannot express their innermost essence, well, in that case there will be no debate at all. (Male, School manager, FG 5 MI, adults)

This is what actually happens in some European societies: the trend is to remove and ban any religious symbol. But this doesn't mean more freedom, it means less freedom for everybody. The question then is not to remove religious symbols and signs of religious belonging. The question is to accept differences (...). We should focus on the way we use the word "different". If we use it as a synonym of "other than/unlike", as the Latin "divertere", it means something characteristic, but also something which takes us far from the others. On the contrary, if we use "different" with the same meaning as the Latin "differo", that is to say that is typical of me, of you, personal and peculiar, this means I can transfer something which is personal in my relationships with others and the others can do the same. In this case, "differences" become something valuable, and of course, they can only be valuable if we consider them as peculiar and unique aspects that we have and that we want to share with the others. If we consider the word "different" as a synonym for other than/unlike, this vision, because of its meaning, will tear us apart and lead to conflict. (Female, Teacher, F G 5 MI, adults)

Other teachers state that the school's laïité is not problem-free, and the risk that a secular education can pose is not considering differences at all, and then denying them together with one's own identity. The fear of triggering conflicts or not having the suitable means to cope with religious contrasts, or establishing which differential treatments can be accepted or not, leads many teachers to remove the problem, reframing it as non-pertinent. The consequence is that "neutrality" turns into "neutralization", with two consequences.

On the one hand, the concerns about extremism, and the strategies to face it, could put an end to classroom debates. On the other hand, managing 
classroom discussions requires specific skills, taking into consideration what is appropriate to discuss in the classroom within the legal and educational systems and cultural context of reference, and with due regard to the age, maturity and aptitudes of students (Jackson, 2019). Teachers feel not prepared to it.

Instead, as seen above, also in the national and the European public debate, in the school public debate carried out by teachers, students and their families, issues that were considered to have been sorted out peacefully (such as tracing the boundaries of freedom of expression, of parental authority, and of religion authority) are regaining the center of attention.

The laïcité implies, besides the duality between private and public spheres, the distinction between the civil and religious spheres. The latter implies the existence of a "religious authority", which succeeds in transforming its absolute truth into dialogue (Rizzi, 2016). This is properly what matters. Then, for schools, the challenge is not to implement cultural divisions, but to encourage the knowledge of all religions, so that each student can learn how to use critical reflection upon one's own religious identity and tradition. Otherwise, no dualism is either applicable or believable (Ibidem: 89).

If we assume that "reflexivity" is a typical feature of Christianity -a religion historically open to reflexivity and to the hermeneutic exercise (Ibidem; Magatti, 2018)-, the RE and mainly the IRC have an extraordinary learning potential. In other words, the cultural heritage of Christianity may be a lever for curriculum enrichment and for promoting constructive dialogue skills among pupils.

In the wake of the European Recommendations, particularly the Recommendation on the Dimension of Religions and Nonreligious Convictions within Intercultural Education (Council of Europe, 2008a), both adults' and students' narratives suggest that the school may represent a privileged space for learning what it means to live in a multi-cultural, multi-religious and multi-ethnic society, that is, learning to become a citizen who peacefully and actively participates in such society. To accomplish this mandate, at least, two more steps need to be taken.

First, the recognition of diversity -and, eventually, agreeing to different treatments-needs to be linked to the fight against the disadvantages related to $i t$. The studies on educational inequalities still give evidence to this phenomenon, with particularly reference to migrants' offspring and pupils' lower education attainment (Ambrosini, Pozzi, 2018; Colombo, Santagati, 2017). In this regard, the school mirrors what happens in the wider society. In Italy, as well as in the rest of Europe, migrants' offspring is affected by the intergenerational transmission of disadvantages in the labor market outcomes, with a higher concentration in low-skilled and "ethnicized" jobs, and in the social mobility process, with little capacity to benefit from the opportunity structure because of both the inequalities constrains and the families' legacies (Zanfrini, 2019). 
All of this, as Zanfrini clearly pointed out, calls into question the prevailing (and "ambivalent") model of integration. The latter is featured by the persistent tension between two opposite aims -on the one hand, recognizing (and managing) the diversity "embedded" in the population with a migrant background, on the other hand, accomplishing the request for equality and uniformity; moreover, it still appears to be incapable of "exploiting" the migrationrelated diversity, despite many attempts (Ibidem).

Secondly, under the same tension, the school needs to find its way for giving value to diversity. This is a priority, as it is for the whole society. Indeed, for society, the enhancement of (migrant-related) diversity may represent a lever to "renew the integration model", thus linking economic competitiveness to social cohesion, viewing migrants as active citizens able to mobilize distinctive potentialities and resources and contributing to the common good (Zanfrini, 2015). For the school itself the intercultural approach that characterizes the Italian educational system represents the best choice to move forward, providing that theoretical principles are translated in classroom practices. Although the Italian intercultural education policies are seen as quite advanced in Europe, the literature underlines the weak correlation between policies, organizational and institutional practices, teaching strategies and educational experiences (Santagati, 2016). As our research suggests, the need to recognize, manage and value religious diversity represents a "test bed" for the intercultural approach and an opportunity to overcome those weaknesses. Acknowledging religion beliefs (as well as atheism) as a fundamental part of one's personal identity, gives to religions "citizenship in the school" and paves the way for an effective interreligious and intercultural dialogue.

When it calls to reflect on the freedom of expression, on the boundaries of responsibilities and limits of claims for different treatments, school becomes a training ground for democratic citizenship and active membership. Beyond the contradiction and difficulties highlighted by focus groups, the participants outline the profile of a public school that is "on the way" to cope with this challenge. The final goal is still far to reach, but it is clearly defined: instead of being a "neutral space", the school will ensure a "safe space" for dialogue (Jackson, 2014). As European Recommendations demand, this is a space where -with appropriate ground rules for constructive discussions in a given normative framework-inclusion and mutual respect are promoted. It is a space in which positive relations with students and parents are daily cultivated, in which students are helped to deal with a plurality of visions, ideas, cultures and religions, to develop critical thinking, to learn how to debate in an atmosphere of mutual tolerance, when they confront each other, and so on (Ibidem). Surely, renewed learning tools, teachers' competences and environmental conditions need to be developed, but first steps have already been taken. 